\title{
Correction to: Leveraging Underwater Cultural Heritage (UCH) Potential for Smart and Sustainable Development in Mediterranean Islands
}

Dionisia Koutsi and Anastasia Stratigea (D)

Correction to:

Chapter "Leveraging Underwater Cultural Heritage (UCH) Potential for Smart and Sustainable Development in Mediterranean Islands" in: O. Gervasi et al. (Eds.): Computational Science and Its Applications - ICCSA 2020, LNCS 12255, https://doi.org/10.1007/978-3-030-58820-5_19

In an older version of this paper, the first author's surname "Koutsi" was placed before their first name "Dionisia". This has been corrected. 